\title{
In-situ emissivity measurement of construction materials
}

\author{
by C. Ciocia*, S. Marinetti*
}

\author{
*ITC-CNR, Corso Stati Uniti 4, 35127 Padova Italy, claudia.ciocia@gmail.com
}

\begin{abstract}
Infrared thermography is a non-destructive diagnostic technique used in the field of constructions as a method for reading of the existing heritage, and represents a model of knowledge of high reliability based on the measurement of physical parameters $[1,2,3,4,5]$. Quantitative information can be achieved once the target emissivity $\varepsilon$ and the reflected temperature $T_{r}$ are known. In this paper, a method to evaluate in-situ the emissivity of building materials is proposed. The measurement procedure is performed in two different steps: firstly, the emissivity values of reference labels are assessed in the laboratory by a dynamic test. Subsequently, the measurement of emissivity is done in situ, under controlled boundary conditions, using the reference labels to characterize the various building materials. The experimental results, in addition to providing information about the tested construction materials, confirm the need for a simple a reliable method to measure emissivity in-situ.
\end{abstract}

Keywords: emissivity, construction materials, thermography, in-situ

\section{Introduction}

The research aim is the development of a procedure for data acquisition to characterize building materials. The materials are referred to those elements of the building construction system, which are the objects of the test. The UNI 8290, technical standard in building design field, provides the classification and the articulation of the technological units and technical elements in which the complex technological system of the building is split up, with their requirements and their performance specifications technology. The technological units are identified with functions cluster technologically compatible, necessary for obtaining environmental performance, while the technical elements are identified with the building products, more or less complex, capable of performing all or part of functions of one or more technology units technology.

The present research refers to three technical elements: the structure of vertical elevation, which is part of the Technology Unit Class "Structure", the plaster which is part of Technology Unit Class " External Partition ", and the vertical window frames which is part of Technology Unit Class " Vertical Closures". These three technical elements, have the functions of bearing wall and finishing and protection of the building and they are made with building materials exposed to the problems of degradation and alteration related to durability and life cycle of the technical element.

The instrumental measuring is a control strategy of the obsolescence conditions of buildings and so an innovative process control of the technical elements is structured, through a process of data acquisition and organization of information for the reconstruction of a knowledge unified framework of the built environment. In this scenario, the diagnostic concept of the performance and diseases of building systems extends to the general evaluation of all the physical performance of the built environment, in order to bring out aspects based on more objective evidence and clarity. With that comes the need to use the diagnostic tools to detect the physical properties of the materials to have a comprehensive framework; the establishment of such quantitative characteristics of the object requires the use of specific techniques to survey data in the infrared.

The acquisition of experimental data is done with infrared thermography [6]. The infrared technique, and in particular the IR thermography, has been applied for many years to evaluate the performance of the building and has been used to identify defects in insulation, air leaks, heat loss through the windows, humidity [7]. Other applications have been made to evaluate the physical parameters of building materials $[8,9]$. The quantitative approach and the temperature measurement with the IR thermography require the knowledge of two important parameters: emissivity of the surface and reflected temperature. While the reflected temperature may be approximately estimated using low emissive targets, emissivity values can be found in the literature for construction materials, or measured in the laboratory on samples, or estimated in-situ. $[10,11]$ It is worth recalling that the emissivity depends strongly on the spectral response of the IR camera used for inspection, and therefore each reference material should be characterized for the specific IR sensor. In this work, two IR cameras with different spectral bands are used: FLIR SC6000 (InSb detector with a 3-5 $\mu \mathrm{m}$ spectral band) and FLIR SC640 (uncooled microbolometer detector with 7.5-13 $\mu \mathrm{m}$ spectral band).

A method for wall emissivity measurement in-situ is proposed. The test is easy to be performed and it takes only a few minutes. 


\section{Experimental procedure}

\subsection{Laboratory reference characterization}

As mentioned above, the method is based on the knowledge of reference emissivity values assessed in the lab for the specific IR camera that will be used for the in-situ inspection. This first step is based on the well-known equation

$$
S_{t o t}=\varepsilon \cdot I_{b b}\left(T_{o}\right)+(1-\varepsilon) \cdot I_{b b}\left(T_{r}\right)
$$

where $S_{\text {tot }}$ is the signal captured by the camera detector composed by emitted and reflected components $\left(\mathrm{W} / \mathrm{m}^{2}\right), \varepsilon$ is the object emissivity in the detector band, $I_{b b}(T)$ is the sensed emissive power received by the sensor from a blackbody at temperature $T\left(\mathrm{~W} / \mathrm{m}^{2}\right), T_{o}$ is the object temperature $(\mathrm{K})$ and $T_{r}$ is the reflected temperature $(\mathrm{K})$.

The estimate of $\varepsilon$ is carried out in a transient regime and in a controlled environment. The use of a contact probe allows to collect the values of $T_{o}$ and individual calibration functions provide the emissive power $I_{b b}\left(T_{o}\right)$. The total signal $S_{\text {tot }}$ is computed from the blackbody temperature provided by the IR camera. $T_{r}$ is maintained constant during the test by means of a shield with large thermal inertia that minimizes the effect of the radiative heat flow caused by the changing temperature of the sample under test. The sample is heated on a stove up to about $20^{\circ} \mathrm{C}$ above room temperature and then, when it has stabilized at around $10^{\circ} \mathrm{C}$ above room temperature, is placed under the shield and its temperature is measured with a calibrated contact probe. At the same time, a thermogram sequence is acquired to collect information about the blackbody apparent temperature. In Table 1, experimental results on white and black paper labels are reported with the $85 \%$ confidence interval $\left(\mathrm{Cl}_{85 \%}\right)$.

Table 1. Emissivity values of white and black paper labels measured with FLIR SC6000 and FLIR SC640

\begin{tabular}{llcl}
\hline \multicolumn{2}{c}{ Sample } & Emissivity & $\mathrm{Cl}_{85 \%}$ \\
\hline \multirow{2}{*}{ Black paper } & FLIR SC6000 & 0.90 & 0.015 \\
& FLIR SC640 & 0.94 & 0.017 \\
\hline \multirow{2}{*}{ White paper } & FLIR SC6000 & 0.72 & 0.010 \\
& FLIR SC640 & 0.93 & 0.023 \\
\hline
\end{tabular}

As expected, the different paper colors are sensed by the MWIR camera, while the LWIR camera provides the same emissivity value for white and black paper. This behavior will be confirmed hereafter for the inspected materials, as well.

\subsection{In-situ measurement}

The second step is performed in-situ and is based on following assumptions:

- $\quad$ emissivity references are available for the specific IR camera used for the test

- $\quad$ the reflected temperature is the same for the references and the target and it is constant during the test

- $\quad$ the references and the target have the same temperature during the test.

The first assumption is satisfied by the laboratory reference characterisation described in Par. 2.1. The use of low and high emissive references, attached on the wall under inspection, allows to solve a system of 2 equations (Eq. (1)) where the unknowns are $T_{o}$ and $T_{r}$. The references used are a black paper label and a polished aluminum foil whose emissivity was verified to be very low. Indeed, tests carried out with FLIR SC6000 provided as result an emissivity of 0.028 with $\mathrm{Cl}_{85 \%}=0.013$.

Concerning the second assumption, the short duration of the considered portion of the cooling process (10-15 s) practically ensures that the reflected temperature is constant during the measurement and its uniformity is controlled by the use of a mobile shield, in equilibrium with the ambient temperature.

The last assumption was verified by means of a FEM simulation with COMSOL Multiphysics. The sketch of the model is shown in figure 1: it is a $20 \mathrm{~mm}$ thick slab (the sample) with 3 labels of 40 microns thickness on its surface. The emissivity of the labels were set according to FLIR SC6000 results (table 1), and the sample emissivity was assumed to be 0.6 . 


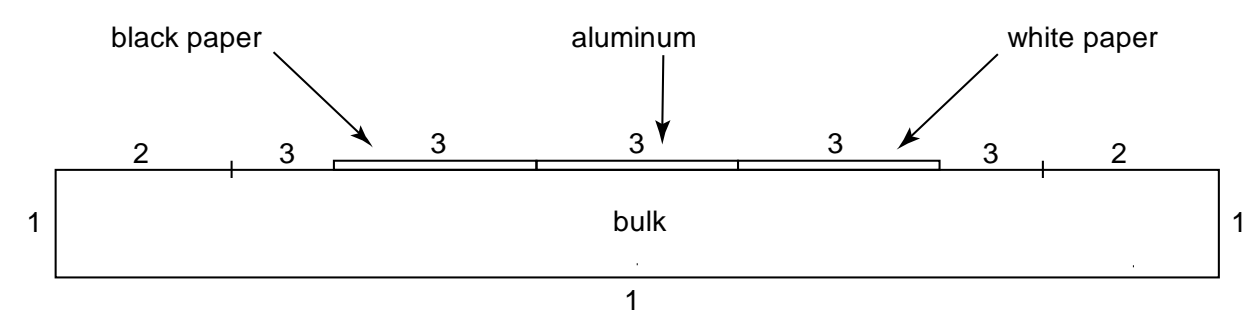

Fig. 1. Model used for FEM simulation

The boundary conditions were set as follows:

- boundary type 1: adiabatic

- boundary type 2: radiative and convective heat exchange with the environment

- boundary type 3: convective uniform heating for a duration of $45 \mathrm{~s}$, and then radiative and convective cooling as for boundary type 2 .

The mean surface temperature on type 3 boundaries is reported in figure 2. To estimate the sample emissivity, the black paper and the aluminum foil are considered to compute $T_{r}$ and $T_{0}$, that are supposed to be the same on all these boundaries. In such a way, $T_{o}$ results to be very close to the black paper temperature.

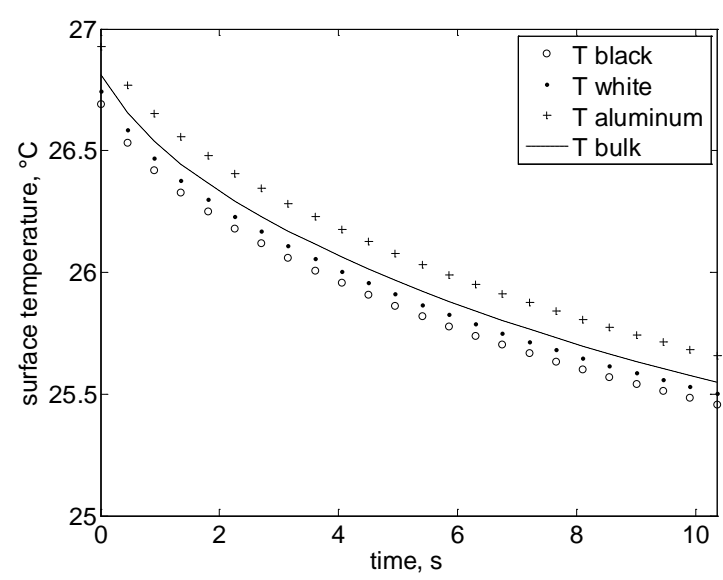

Fig. 2. Temperature vs time on type 3 boundaries

Since the sample temperature differs of about $0.15^{\circ} \mathrm{C}$ from $T_{0}$, the estimated emissivity, averaged on the $10 \mathrm{~s}$ time interval, is affected by a systematic error $(\varepsilon=0.625$ instead of 0.6$)$. The same considerations can be made for the white paper whose estimated emissivity is 0.732 . The use of white paper is useful when performing in-situ tests in order to check that all assumptions are met.

Although these errors are small, since they are systematic, it is recommended to improve model in order to minimize them. These errors are due to the additional thermal resistances and to the different emissivity of the references and the sample. To make more uniform the temperature distribution during the very beginning of the cooling stage, a modified model is proposed (figure 3).

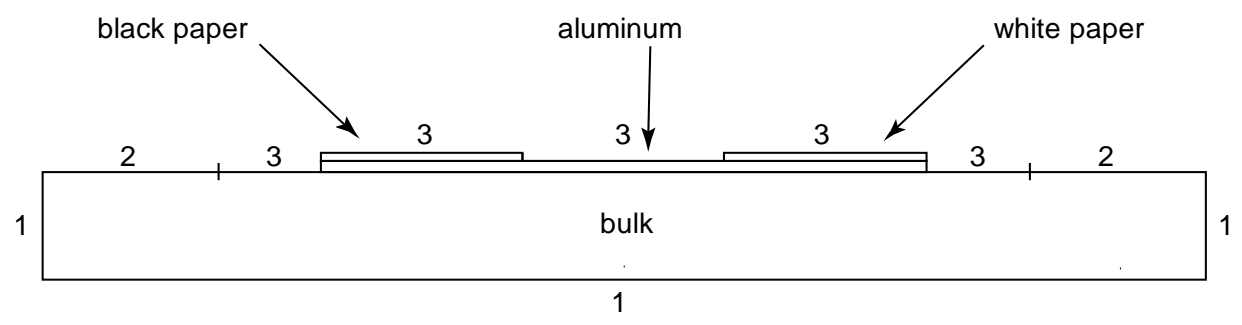

Fig. 3. Improved model used for FEM simulation 
The paper labels are applied on a 60 micron thick aluminum layer in order to enhance the lateral heat diffusion. In such a way the surface temperature is more uniform as it can be seen in figure 4 . The estimated emissivities of the sample and the white paper label are now respectively 0.610 and 0.725 .

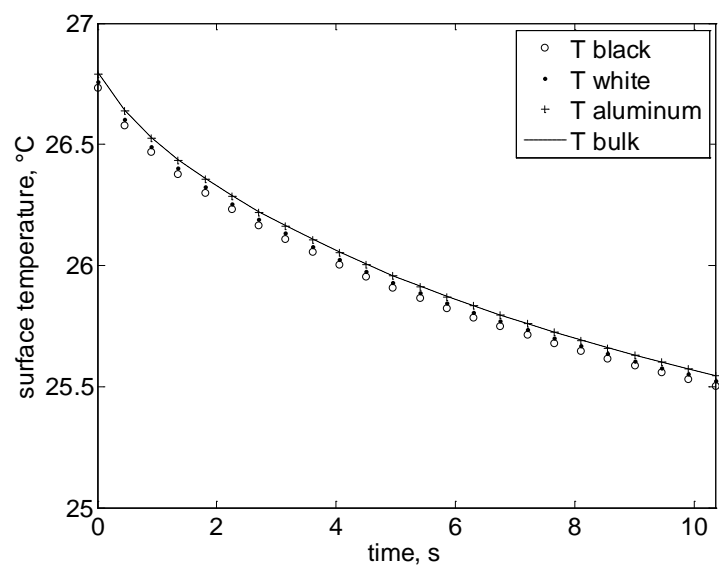

Fig. 4. Temperature vs time on type 3 boundaries with the improved FEM model

Finally, according to the simulation results the procedure for in-situ measurements is defined as follows:

- the adhesive target is characterized and prepared in laboratory overlapping some layers of aluminum foils and one layer of paper labels

- the convective heating is provided through a heat gun equipped with a viewfinder to center the target in order to uniformly heat the region of interest

- $\quad$ the heating duration is chosen to produce a sufficient temperature increase without letting the thermal front interest possible subsurface inhomogeneities

- the use of a mobile shield allows to control the reflected temperature whose value is not needed to be known

- IR images are acquired during the first 10-15 $\mathrm{s}$ of the cooling stage (air temperature and humidity are set into the software to correctly take into account the atmosphere contribution)

The measurements were made on plasterboard finishing, plastered walls with traditional plaster made of lime mortar and building materials such as pumice, gasbeton, glass, wood, white marble.

As for the plasterboard, it is laid in place with a metal frame with rails and uprights of different sizes and thickness of sheet metal, to which are screwed the sheets of plasterboard. The traditional plaster is made of hydraulic lime mortar and is constituted by three layers, "rinzaffo, sottovallo e arricciatura". The rinzaffo is a layer of lime mortar used to smooth the surface of the wall when it is particularly bumpy. The sottovallo is a layer of mortar of relatively small thickness applied directly to the masonry or on the first layer and the arricciatura is a layer of small thickness of mortar used to make the wall surface perfectly flat plastered, before proceeding to the traditional painting.

The first test was made on the traditional plaster and, to validate the proposed method, the same sample was tested with the technique described in paragraph 2.1 which involves the use of a temperature contact probe. The experimental results are reported in Table 2.

Table 2. Validation of the proposed method on a traditional plaster sample

\begin{tabular}{cc|cc}
\hline \multicolumn{2}{c|}{ Laboratory method } & \multicolumn{2}{c}{ In-situ method } \\
\hline Emissivity & $\mathrm{Cl}_{85 \%}$ & Emissivity & $\mathrm{Cl}_{85 \%}$ \\
0.71 & 0.022 & 0.72 & 0.022 \\
\hline
\end{tabular}

Other tests were carried out on both small dimension samples and real size internal partition. As an example, in figure $5 a$ the reference target applied to a white marble slab is shown. 


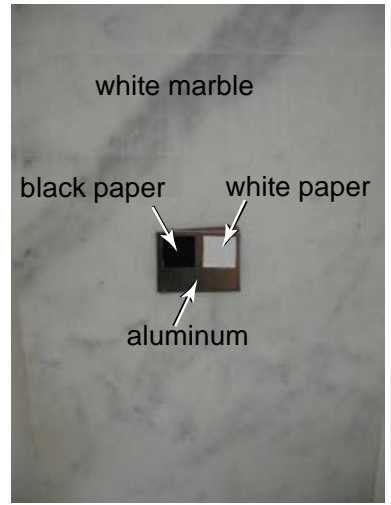

a

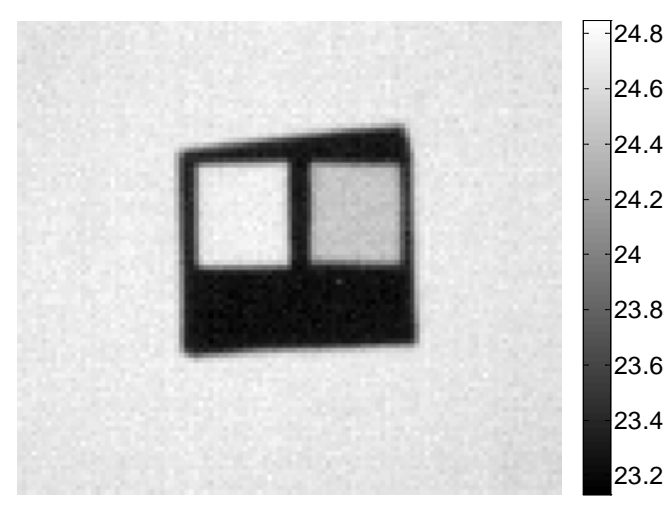

$b$

Fig. 5. The reference target used for emissivity estimation on a white marble slab(a); thermogram acquired on the white marble slab (b)

After heating the sample for $45 \mathrm{~s}$, a sequence of 100 thermograms was acquired with FLIR SC6000 camera at a frequency of $10 \mathrm{~Hz}$. Figure $5 \mathrm{~b}$ shows the region of the first available IR image corresponding the type 3 boundaries in figure 3 . The colorbar is not to be interpreted as a real surface temperature, but as the blackbody temperature corresponding to the total radiation collected by the sensor (emitted and reflected by the sample surface). Indeed the sequence was acquired setting the emissivity of all the pixels to 1.

The behavior of the computed emissivity of the white paper is shown in figure $6 \mathrm{a}$. As it can be noticed, there is not a noticeable trend and the mean value, although overestimated as predicted by the FEM model, is in quite good agreement with the value reported in table 1 . Moreover, the estimated reflected temperature (figure $6 \mathrm{~b}$ ) does not change significantly as required from the second assumption.

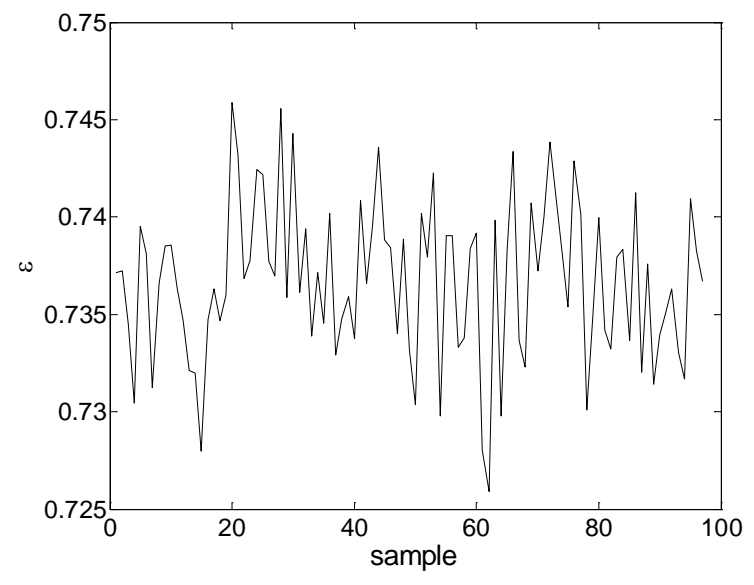

a

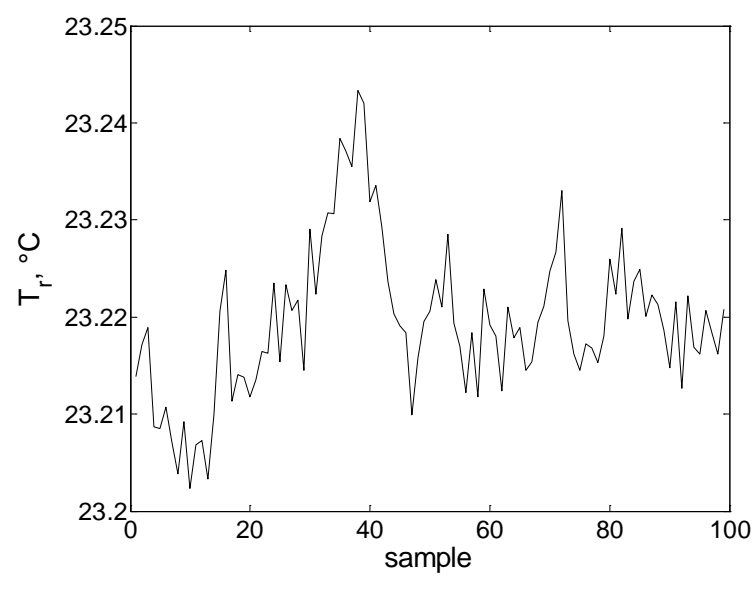

$b$

Fig. 6. Emissivity of white paper with FLIR SC6000 (a); estimated reflected temperature (b)

This means that all the assumptions aforementioned are met and the test, in the region around the reference, can be considered reliable. It is worth noting that the role of the white paper is important, since it represents the chance the operator has to check the validity of the undergoing test.

Finally, figure 7 shows the result of a single test on a white marble slab. Also in this case, there is no trend on the $10 \mathrm{~s}$ time interval considered. 


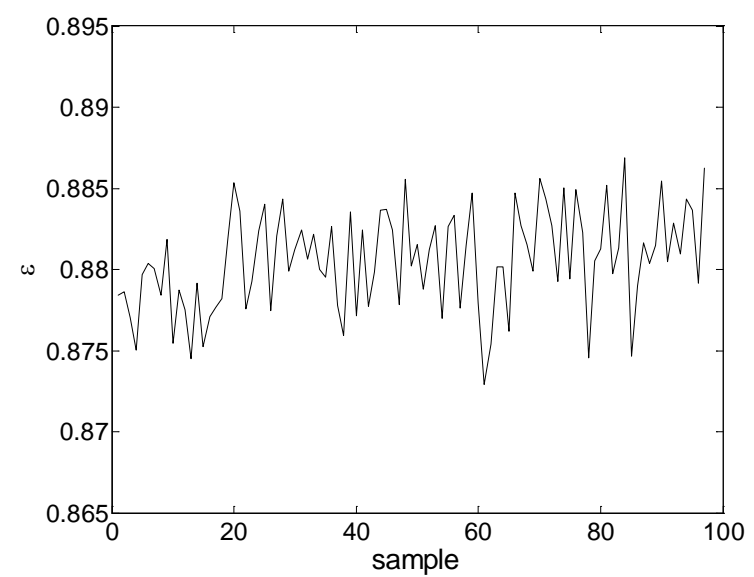

3

Fig. 7. Emissivity of white marble with FLIR SC6000

\section{Results}

In table 3 experimental results of tests carried out with both MWIR and LWIR cameras are reported. As expected, the comparison underlines that emissivity in the LWIR windows is generally higher than that in the MWIR. Hence, it is important to carefully use the tabulated values when they refer to a wavelength spectrum that is different from that of the IR camera used.

Table 3. Emissivity values of construction materials measured with InSb and microbolometer cameras

\begin{tabular}{lcc|cc}
\cline { 2 - 5 } Sample & \multicolumn{2}{c|}{ SC6000 } & \multicolumn{2}{c}{ SC640 } \\
\hline Plasterboard finishing & 0.51 & 0.040 & 0.80 & 0.016 \\
Glass & 0.91 & 0.037 & 0.87 & 0.024 \\
Plywood clear & 0.62 & 0.021 & 0.79 & 0.024 \\
White marble & 0.87 & 0.027 & 0.92 & 0.025 \\
\hline
\end{tabular}

Further tests were carried out with the FLIR SC6000 on other materials and results are reported in table 4.

Table 4. Results of further tests carried out with an InSb sensor

\begin{tabular}{lcc}
\hline Sample & Emissivity & $\mathrm{Cl}_{85 \%}$ \\
\hline Traditional plaster & 0.71 & 0.022 \\
Pumice & 0.68 & 0.034 \\
Gasbeton & 0.67 & 0.043 \\
\hline
\end{tabular}

\section{Conclusions}

The goal of this paper is to give a contribution to the effectiveness of infrared thermography as a diagnostic method for the built heritage. From the diagnostic studies carried out on the surfaces of the buildings, infrared thermography proved to be a useful tool to provide valuable information for materials evaluation. In particular, it can be efficiently used for the quantitative assessment of the materials, by measuring the emissivity parameter in situ.

The emissivity of different building materials, such as plasters, marbles and stones was measured in situ, at $3^{\circ} \mathrm{C}-5^{\circ} \mathrm{C}$ above the surrounding temperature. The samples were investigated in the MWIR and LWIR windows, using the 
same procedure. Results confirmed that there are materials that have high emissivity in both spectra, like white marble, while others, like wood and plasterboard finishing, must be characterized in each IR window.

Since in literature there is not much on in-situ emissivity measurement of building materials, this work provides, in addition to valuable information on the tested materials, a reliable method that can be easily applied by thermographers operating in the field of buildings conservation and cultural heritage protection.

\section{REFERENCES}

[1] Avdelidis N.P., Moropoulou A., "Emissivity considerations in building thermography", Energy Build 2003;35:6637.

[2] Moropoulou A., Aggelakopoulou E., Avdelidis N.P., Koui M., "Non-destructive techniques for the characterization of structural materials", E.P. Douglas, O.D. Dubon Jr, J.A. Isaacs, W.B. Knowlton, M.S. Whittingham (Eds.), The Undergraduate Curriculum in Materials Science and Engineering, vol. 760E, Materials Research Society, Pittsburgh, 2003, Electronic Publication.

[3] Grinzato E., Bison P.G., Marinetti S., "Monitoring of ancient buildings by the thermal method", Journal of Cultural Heritage 3 (2002) 21-29.

[4] Moropoulou A., Avdelidis N.P., Koui M., Kanellopoulos N.K., "Dual band infrared thermography as a NDT tool for the characterization of the building materials and conservation performance in historic structures", T. Matikas, N. Meyendorf, G. Baaklini, R. Gilmore (Eds.), Nondestructive Methods for Materials Characterization, vol. 591, Materials Research Society, Pittsburgh, 2000, pp. 169-174.

[5] Dana, R.W., 1969. "Measurement of 8-14 micrometer emissivity of igneous rocks and mineral surfaces", NASA Sci. Rep. NSG-632, GSFC, Greenbelt, MD.

[6] Avdelidis N.P., Moropoulou A., "Infrared thermography. Philosophy, history, approaches, applications and standards", Proceedings of the Fourth National Conference of HSNT and the Second Balkan Conference of BSNDT, Athens, Greece, 2002.

[7] Moropoulou A., Avdelidis N.P., Review Paper: "Applications of infrared thermography for the investigation of historic structures". J. Cult. Heritage, (2004), pp. 119-127.

[8] Moropoulou A., Avdelidis N.P., "Emissivity measurements on historic building materials using dual wavelength infrared thermography", A.E. Rozlosnik, R.B. Dinwiddie (Eds.), Thermosense XXIII, SPIE Press, Orlando, Florida, USA, 2001, pp. 224-228.

[9] Moropoulou A., Avdelidis N.P., Aggelakopoulou E., Griniezakis, Koui M., Aggelopoulos A., Karmis P. and Uzunoglou N.K., "Examination of plastered mosaic surface using NDT techniques", J. Insight, 43 (2001), pp. 241-243.

[10] Moropoulou A., Avdelidis N.P., "The role of emissivity in infrared thermographic imaging and testing of building an structural materials", X.P.V. Maldague, A.E. Rozlosnik (Eds.), ThermosenseXXIV, SPIE Press, Orlando, Florida, USA, 2002, pp. 281-287.

[11] Moropoulou A., Avdelidis N.P., Koui M., Tzevelekos I., "Determination of emissivity for building materials using infrared thermography", Journal of Thermology International 10 (3) (2000) 115-118. 